\title{
Simultaneous data-based optimization of a 1D-ecosystem model at three locations in the North Atlantic: Part II-Standing stocks and nitrogen fluxes
}

\author{
by Markus Schartau ${ }^{1,2}$ and Andreas Oschlies ${ }^{3}$
}

\begin{abstract}
This study relates the performance of an optimized one-dimensional ecosystem model to observations at three sites in the North Atlantic Ocean: the Bermuda Atlantic Time Series Study (BATS, 31N 64W), the location of the North Atlantic Bloom Experiment (NABE, 47N 20W), and Ocean Weather Ship INDIA (OWS-INDIA, 59N 19W). The ecosystem model is based on nitrogen and resolves dissolved inorganic nitrogen $(N)$, phytoplankton $(P)$, zooplankton $(Z)$ and detritus $(D)$, therefore called the NPZD-model. Physical forcing, such as temperature and eddy diffusivities are taken from an eddy-permitting general circulation model of the North Atlantic Ocean, covering a period from 1989 through 1993. When an optimized parameter set is applied, the recycling of organic nitrogen becomes significantly enhanced, compared to previously published results of the NPZDmodel. The optimized model yields improved estimates of the annual ratio of regenerated to total primary production ( $f$-ratio). The annual $f$-ratios are $0.09,0.31$, and 0.42 for the locations of BATS, NABE, and OWS-INDIA, respectively. Nevertheless, three major model deficiencies are identified. Most conspicuous are systematic discrepancies between measured ${ }^{14} \mathrm{C}$-fixation rates and modeled primary production under nutrient depleted conditions. This error is primarily attributed to the assumption of a constant carbon-to-nitrogenratio for nutrient acquisition. Secondly, the initial period of the modeled phytoplankton blooms is hardly tracked by the model. That particular model deficiency becomes most apparent at the OWS-INDIA site. The interplay between algal growth and short-term alterations in stratification and mixing is believed to be insufficiently resolved by the physical model. Eventually, the model's representation of the vertical nitrogen export appears to be too simple in order to match, at the same time, remineralization within the upper 300 meters and the biomass export to greater depths.
\end{abstract}

\section{Introduction}

When investigating complex biological systems, numerical models can help to extrapolate information from generally sparse observations to a more complete picture. To this extent, models are developed which attempt to combine our current knowledge of the system's individual subordinated processes. One important focus of marine ecosystem

1. Alfred-Wegener-Institut für Polar- und Meeresforschung, Bussestr. 24, 27670 Bremerhaven, Germany.

2. Present address: Marine Sciences Research Center, SUNY, Stony Brook, New York, 11794, U.S.A. email: markus.schartau@stonybrook.edu

3. Institut für Meereskunde, Düsternbrooker Weg 20, 24105 Kiel, Germany. 
modeling is the biological carbon pump, which describes the photosynthetical fixation of dissolved inorganic carbon into organic carbon (primary production) and its export into the deep ocean (Volk and Hoffert, 1985). While direct variations of inorganic and organic carbon concentrations due to biological processes are difficult to determine against high background values, one can exploit the fact that biological production in the light-lit surface layer is usually limited by the availability of either nitrogen or phosphorus. Hence, modeling the cycling of nitrogen or phosphorus can be regarded as a first approximation to modeling the biological carbon pump. Although exceptions exist, e.g. iron limitation, such an approximation can be regarded as a good starting point. However, an assumption is needed in order to determine the formation of organic carbon from modeled nitrogen fluxes. In many cases fixed stoichiometric carbon-to-nitrogen ratios are presumed for the uptake of nutrients by marine phytoplankton, such as reported by Redfield et al. (1963). Consequently, when referring to a relatively simple ecosystem model and relying on the assumption of a fixed C:N stoichiometry, one has to expect certain model limitations. Yet, it has not been clarified whether particular model restrictions, such as being exclusively based on nitrogen or disregarding higher trophic levels, produce biased estimates of either nitrogen or carbon fluxes.

The most fundamental theoretical framework for a marine biological environment solely regards the conservation of the number of atoms. It is the fact that different ecosystems are dominated by different organisms which naturally leads to the question whether it is possible to construct a marine ecosystem models with applications to different regions at the same time. So far, a number of efforts have been made along this line (e.g. Sarmiento $e t$ al., 1993; Six and Maier-Reimer, 1996; Oschlies and Garçon, 1998) under the assumption that physics rather than details in biology control the ecosystems. Certainly, sophisticated physics is a prerequisite for improved biogeochemical simulations, but the structure of the biological models will influence biogeochemical flux estimates as well. Many model investigations of the last ten years were motivated by (and contributed to) the Joint Global Ocean Flux Studies (JGOFS). It has been stressed that many models are fitted to one particular site (e.g. Hurtt and Armstrong, 1996; Evans, 1999; Fasham and Evans, 2000; Spitz et al., 2001) and may thereby lose their ability to be applicable to different sites or larger scales (Doney et al., 2002). One way of solving this problem would be to increase the model complexity and to raise the number of tunable parameters. Generally this means allowing for a higher degree of freedom for improved fits to observations at individual sites. The question then becomes where and how to expand oversimplified ecosystem models and to what extent the number of degrees of freedom must be raised. In spite of increasing computational power we still face restrictions on the complexity of biological models in order to remain simple enough to be coupled to high resolution basin-scale circulation models. Although capturing a great deal of biological variability, coupled models still show deficiencies when their results are compared with time series observations at different locations (e.g. Fasham et al., 1993; Oschlies et al., 2000). To a certain degree these deficiencies can be attributed to an inappropriate set of parameter values. 
Hence, for an automated data-model comparison it is advantageous to have uncertainties reduced which are related to the choice of parameter values. To date we cannot determine the best parameter values right away, since the parameterizations in the model represent a diversity of individual organisms and are likely to include processes which are not known or understood. Note that this is always the case, no matter how extensive the model is. In addition, organisms in the open ocean will never grow under balanced conditions and hence it is not straightforward to directly apply parameters obtained from laboratory experiments. Therefore, for any particular model version a best suited parameter set has to be determined. One possibility to achieve this is to reduce the misfit between observational data and model results (often referred to as cost function), either by hand tuning or by applying search algorithms for automated parameter optimization. Having reduced major data-model misfits through an optimal choice of parameter values, one can analyze the model performance with a special focus on the identification of remaining model errors. Such investigations can help to guide future model improvements. It is of likewise importance to avoid redundant parameterizations that cannot be constrained and, therefore, introduce a variety of possible model solutions.

The aim of this study is to relate the performance of an ecosystem model to existing observations at three locations ( $31 \mathrm{~N} 64 \mathrm{~W}, 47 \mathrm{~N} 20 \mathrm{~W}$, and 59N 19W) in the North Atlantic which, according to Longhurst (1998), belong to three different biogeochemical provinces. This is achieved by a simultaneous synthesis of observations and model results at the distinct sites. With the NPZD-model, optimized flux rates can be determined from the assimilation of standing stock observations, such as chlorophyll $a$ concentrations ( $\mathrm{Chl} a$ ) and nitrogen biomass. The ecosystem model and optimization procedure are described together with the optimal parameter set in an accompanying paper (Schartau and Oschlies, 2003; this issue). Our investigations presented hereafter are subject to three major questions: (1) Can a simple NPZD-model with a single optimized parameter set sufficiently characterize the differences between different biogeochemical regions? (2) Which deficits in physical forcing and model structure are responsible for a poor fit to observations? (3) What are the implications for future model refinements?

\section{Method}

\section{a. Brief model description}

The biological model resolves dissolved inorganic nitrogen $(N)$, phytoplankton $(P)$, zooplankton $(Z)$ and detritus $(D)$, and is, therefore, named $N P Z D$-model. The full model equations are listed in the Appendix of the accompanying paper (Schartau and Oschlies, 2003; this issue). The NPZD-model is similar to the biological component of the basin-wide model of Oschlies and Garçon (1999) and Oschlies et al. (2000) (hereafter referred to as OG-model). Few modifications to the original OG-model have been conducted to enhance the recycling of nutrients and to better resolve deep chlorophyll maxima in oligotrophic regions: Formulations for the phytoplankton mortality rates are 
adopted from Oschlies (2001), which implies a quadratic mortality that should approximate the loss of phytoplankton due to the formation of aggregates (Doney et al., 1996). As a consequence, this phytoplankton loss must enter the detritus compartment which sinks through the water column. The phytoplankton's linear nitrogen loss is also modified and now enters the dissolved nitrogen compartment directly. This may be regarded as an implicit description of the bacterial loop without explicitly including bacteria and dissolved organic nitrogen (DON) as additional state variables in the model. A fraction of the phytoplankton's nitrogen is lost via exudation, leakage or cell lysis and is rapidly remineralized. Although being a crude approximation, we wish to have this pathway available since the role of effective remineralization of organic nitrogen has been emphasized as important to model biogeochemical fluxes in oligotrophic regions (Spitz et al., 2001). Another modification with respect to the original OG-model is the implementation of a variable chlorophyll-to-nitrogen (Chl $a: \mathrm{N})$ ratio, as an empirical relationship originally proposed by Cloern et al. (1995). Self shading remains a function of phytoplankton biomass (in nitrogen units) rather than of chlorophyll, thereby eliminating the potential impact of variable Chl $a: \mathrm{N}$ ratios on the simulated light distribution with depth. The last modification with respect to earlier versions of the model is that now all remineralization rates are assumed to be temperature dependent.

The physical forcing, such as temperature and eddy diffusivities are taken from simulations with a general ocean circulation model of the North Atlantic forced by daily mean reanalysis data of the European Center of Medium Range Weather Forecast (ECMWF). Surface radiation data are taken directly from the ECMWF reanalysis set. The initial conditions for the vertical nitrate profiles are taken from Conkright et al. (1994) at all three sites of interest. The spin-up time equals two years, with repeated forcing data from 1989. After that, a period of five years is simulated (1989 through 1993). The generally good performance of the physical model is described elsewhere (Oschlies et al., 2000) and we, therefore, leave out a detailed analysis of the physical variables. Diapycnal diffusivities are computed by a turbulent-kinetic-energy scheme based on Gaspar et al. (1990). Figure 1 shows modeled mixed layer depths at the different sites together with monthly mean values obtained from the Levitus and Boyer (1994) climatology. At the BATS site the model shows good agreement with observations, which was already discussed in Schartau et al. (2001). Interannual variations between 1989 through 1993 are most pronounced at the NABE site. The modeled mixing depths at OWS-INDIA are generally deeper than those derived from observations. The effect on the nitrate supply to the upper layers due to errors in deep winter mixing is negligible, because at OWS-INDIA the vertical gradient of dissolved inorganic nitrogen becomes tiny below 500 meter depth.

\section{b. Calculation of nitrogen fluxes}

Essentially all parameters of ecosystem models describe exchange rates between the individual model compartments (e.g. growth rates, grazing rates, mortality rates). Such flux rates are difficult to measure in situ. By employing parameter values obtained through the 

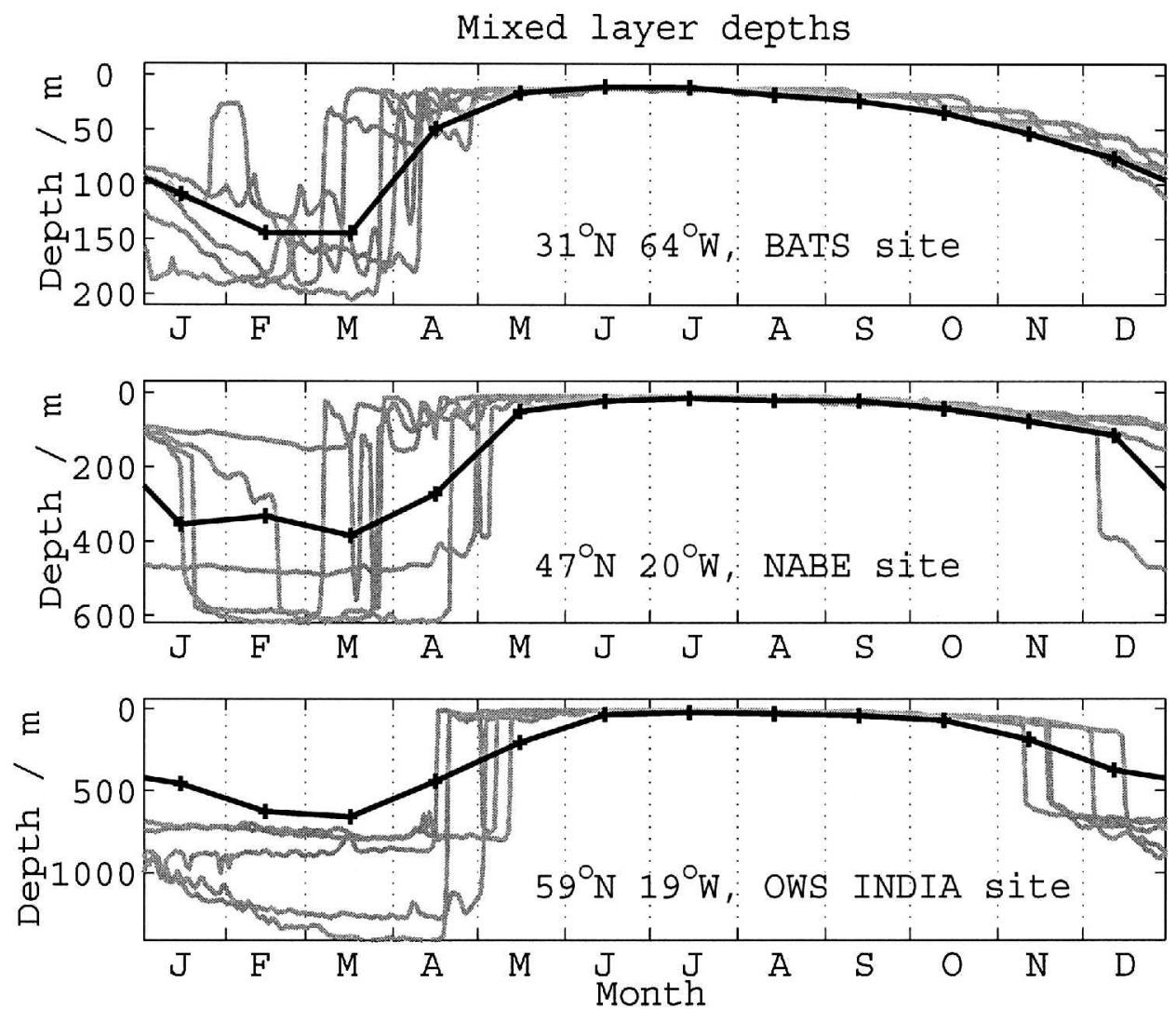

Figure 1. Gray lines show modeled mixed layer depths for the years 1989 through 1993 projected into a single year. Modeled mixed layer depths were determined with a $0.2^{\circ} \mathrm{C}$ temperature criterion. The solid black line indicates typical monthly mean mixed layer depths derived from observations, according to Levitus and Boyer (1994).

optimization procedure, we actually generate a best guess of nitrogen fluxes for the $N P Z D$-model. In this way, optimal flux estimates can be retrieved from the assimilation of standing stock observations, such as Chl $a$ and particulate organic nitrogen (PON), together with primary production measurements, into the model. The model's individual annual fluxes between the compartments are calculated from an ensemble of model runs. This allows us to relate uncertainties in the optimal parameter estimates to uncertainties in the model results. To this end we generate 500 random parameter combinations from a Gaussian distribution with variances which correspond to the parameter error estimates of Schartau and Oschlies (2003; this issue). Note that the errors of the resulting model fluxes may deviate from a Gaussian distribution. Since a determination of the correct error distribution is far beyond the scope of this paper, we confine our analysis to the calculation of mean and standard deviations of those fluxes obtained from the 500 model runs. 
Table 1. Collected results from the three sites of BATS, NABE and OWS-INDIA. Modeled winter mixed layer depths were estimated while applying a $\Delta T \geq 0.2$ criterion. Observed mixed layer depths are taken from Levitus and Boyer (1994). The DIN draw-down is the difference between maximum winter and minimum summer concentration, within the upper 10 meters. Satellite estimates of primary production are according to: ${ }^{a}$ Sathyendranath et al. (1995), ${ }^{\mathrm{b}}$ Antoine et al. (1996), and ${ }^{\mathrm{c} B e h r e n f e l d}$ and Falkowski (1997). Details on our approximation of the $f$-ratio are described in the text. Observational estimates are taken from literature: ${ }^{\mathrm{d}}$ Laws et al. (2000), ${ }^{\mathrm{e}}$ Martin et al. (1993), ${ }^{\mathrm{f}}$ Buesseler et al. (1992), ${ }^{\mathrm{g}}$ Garside and Garside (1993), ${ }^{\mathrm{h}}$ Boyd et al. (1997).

North Atlantic Ocean

Winter MLD/meter

$\Delta \mathrm{DIN} / \mathrm{mmol} \mathrm{m}^{-3}$

(winter maximum -

summer minimum)

Mean PON/mmol m $\mathrm{m}^{-3}$

Model (min/max)
$\langle$ Observation $\rangle$
Model (min/max)

$\langle$ Observation $\rangle$
Model
$\quad$ (spring/summer)
$\langle$ Observation $\rangle$
$\quad$ (spring/summer)
Model (min/max)
$\langle$ Satellite $>$

Model

〈Observation〉
$31 \mathrm{~N} 64 \mathrm{~W}$

$189 / 104$

145

$0.4 / 0.2$

0.5

$0.3 / 0.2$

$0.4 / 0.3$

$88 / 120$

$99^{\mathrm{a}} / 88^{\mathrm{b}} / 122^{\mathrm{c}}$

0.09

$0.1-0.14^{\mathrm{d}}$
$47 \mathrm{~N} 20 \mathrm{~W}$

$615 / 129$

385

$10.3 / 6.1$

7

$0.5 / 0.7$

$1.1 / 0.6$

$145 / 160$

$179^{\mathrm{a}} / 112^{\mathrm{b}} / 212^{\mathrm{c}}$

0.31

$0.16-0.6^{\mathrm{d}, \mathrm{e}, \mathrm{f}, \mathrm{g}}$
59N 19W

$1382 / 763$

650

$15.4 / 11.7$

\section{2}

$0.1 / 0.8$

$$
-/ 0.9
$$

$104 / 119$

$313^{\mathrm{a}} / 124^{\mathrm{b}} / 255^{\mathrm{c}}$

0.42

$0.62-0.93^{\mathrm{h}}$

\section{Results}

In Table 1 we list some major model results at the three sites of interest and compare them with the observational counterparts. Pronounced differences between the different locations are identifiable both in the observations and in the model results, with a relatively good agreement of the two. We will first present a more detailed analysis of the standing stocks, such as DIN, PON and Chl $a$. Thereafter, the optimized annual nitrogen fluxes will be compared among the three distinct sites.

\section{a. Standing stocks}

i. Dissolved inorganic nitrogen (DIN). In Figure 2, observed and modeled DIN inventories of the euphotic zone are shown for all three locations. The BATS site belongs to the western part of the North Atlantic Subtropical Gyral Province (W-NAST, Longhurst, 1998). The prevailing conditions at this site are characterized as oligotrophic. Being in good agreement with observations, the optimized upper-ocean DIN inventory of the model is very small. Minor discrepancies exist for the late summer inventories, from August through October, but modeled winter and spring concentrations fall well within the range of observations. The modeled vertical DIN gradients are also similar to those observed (not shown). There is little seasonal variability in the integrated DIN content of the upper 126 meters. 

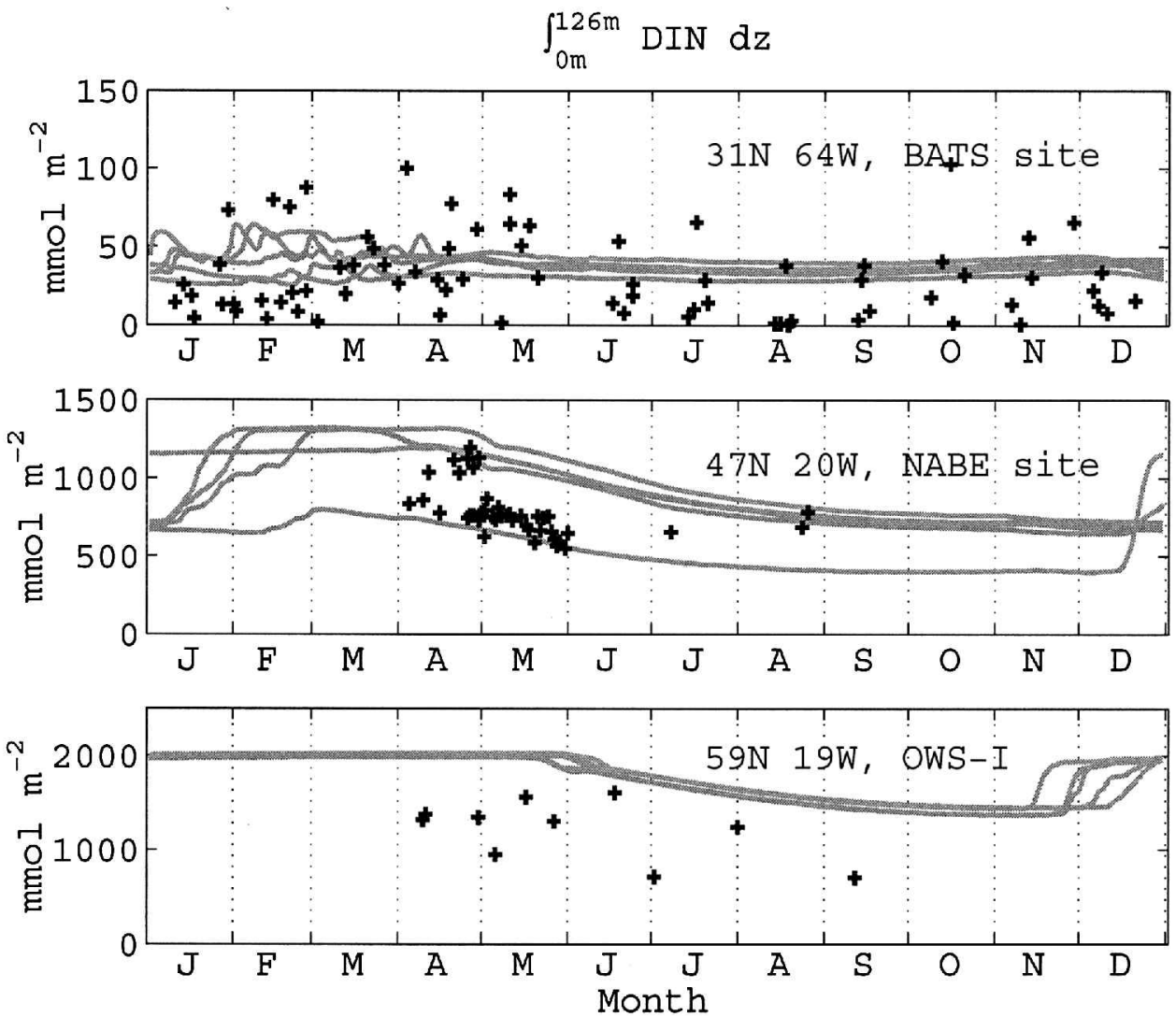

Figure 2. Dissolved inorganic nitrogen (DIN) integrated over the upper 126 meters at the three North Atlantic sites. Gray lines show model solutions from 1989 through 1993 projected into a single year. Observations are indicated by bold marks. Going from the oligotrophic BATS site toward higher latitudes reveals a significant increase in DIN concentrations.

The picture changes when referring to model results at the NABE site, middle graph of Figure 2. Interannual variations are much more pronounced than at the other two locations. In winter 1991 through spring 1992 mixing reached down to a maximum of 130 meters, which was significantly shallower than usual (Fig. 1). As a consequence, the decreased mixing depth enables a biological response in early spring. Since phytoplankton growth is usually limited by light during February and the beginning of March, the initialization of a phytoplankton bloom is extremely sensitive to interannual variations in winter mixing at the NABE site. Note that observational data used for assimilation are mostly associated with NABE measurements (Ducklow and Harris, 1993) and are, therefore, biased toward those conditions found in the year 1989. Looking in more detail, the model results of 1989 show some deviations from observations in winter nitrate concentrations. The modeled maximum winter concentration is close to $10.4 \mathrm{mmol} \mathrm{N} \mathrm{m}^{-3}$ from end of February until 
mid April, whereas observed nitrate concentrations were $6 \mathrm{mmol} \mathrm{N} \mathrm{m}^{-3}$ on April 25, shortly before the phytoplankton bloom commenced. For the same location, similar discrepancies were obtained by the three-dimensional ecosystem-circulation model of the North Atlantic when forced by climatological data (Oschlies et al., 2000), with even deeper mixed layers $\left(700 \mathrm{~m}\right.$ ) and winter concentrations of up to $13 \mathrm{mmol} \mathrm{N} \mathrm{m}{ }^{-3}$. When focusing on the same period, Marra and Ho (1993) were able to simulate the observed nitrate time-depth distribution in spring 1989, starting from observed nitrate concentrations as initial condition. After two years of spin up our model solution shows almost no sensitivity to the initial conditions. In any case, the modeled DIN removal seems correct in magnitude (Table 1), but its draw-down is somewhat too slow at $47 \mathrm{~N} 20 \mathrm{~W}$. This can be attributed to the fast recycling flux of $0.1 \mathrm{mmol} \mathrm{N} \mathrm{m}{ }^{-2} \mathrm{~d}^{-1}$ from the phytoplankton pool directly back to DIN during the first 15 days of the bloom.

In contrast to the BATS and NABE locations the literature seems rather scarce for nitrogen inventories at OWS-INDIA. Among the three model locations the site of the OWS-INDIA is the most northern one and belongs to the southern part of the Atlantic Subarctic Province (SARC), which is influenced by the North Atlantic Current system that transports subtropical water toward the Arctic Ocean. The most evident mismatch between modeled and observed physics are the mixing depths in winter, with the model yielding maximum mixing depths close to $1000 \mathrm{~m}$ in contrast to observed depths close to $600 \mathrm{~m}$. The onset of the spring stratification is delayed in the model which strongly influences the biological response. Accordingly, the modeled draw-down in nitrate is initiated in May rather than end of March or beginning of April as actually observed. The modeled amount of nitrate removal is still in accordance with observations (Table 1). It is frequently documented that nitrate does not become depleted in summer. Even in August, the observed monthly means do not fall below $1 \mathrm{mmol} \mathrm{N} \mathrm{m}^{-3}$ at near-surface depths with a maximum in primary production. Our model results show a similar picture, approximately $2 \mathrm{mmol} \mathrm{N} \mathrm{m}{ }^{-3}$ remain unutilized despite relatively high production rates. It is noteworthy that no co-limitation by other nutrients (e.g. iron) is accounted for by the model.

ii. PON. Looking at the PON inventories, Figure 3 shows one remarkable feature: the integrated concentrations of PON do not differ as much among the three sites as they do for DIN. Actually, differences in the winter to summer draw-down of DIN are huge compared to those in observed and modeled mean PON concentrations (Table 1). In order to maintain similar PON concentrations, the nitrogen flux rates must, therefore, differ significantly which can be inferred from the $f$-ratios as well. Similar to DIN, the PON inventory at the Bermuda site contains a very small seasonal signal. The modeled build-up of PON is in very good agreement with observations during the spring period. Simulated PON concentrations become largest in May between 65 and 90 meters depth, predicting 0.45 and $0.6 \mathrm{mmol} \mathrm{N} \mathrm{m}^{-3}$ for the years 1990 and 1992 . Concentrations close to $0.6 \mathrm{mmol} \mathrm{N} \mathrm{m}^{-3}$ are observed at shallower depths, typically ranging from 30 to 80 meters. The model slightly underestimates the observed PON measurements below 100 meters. This produces 

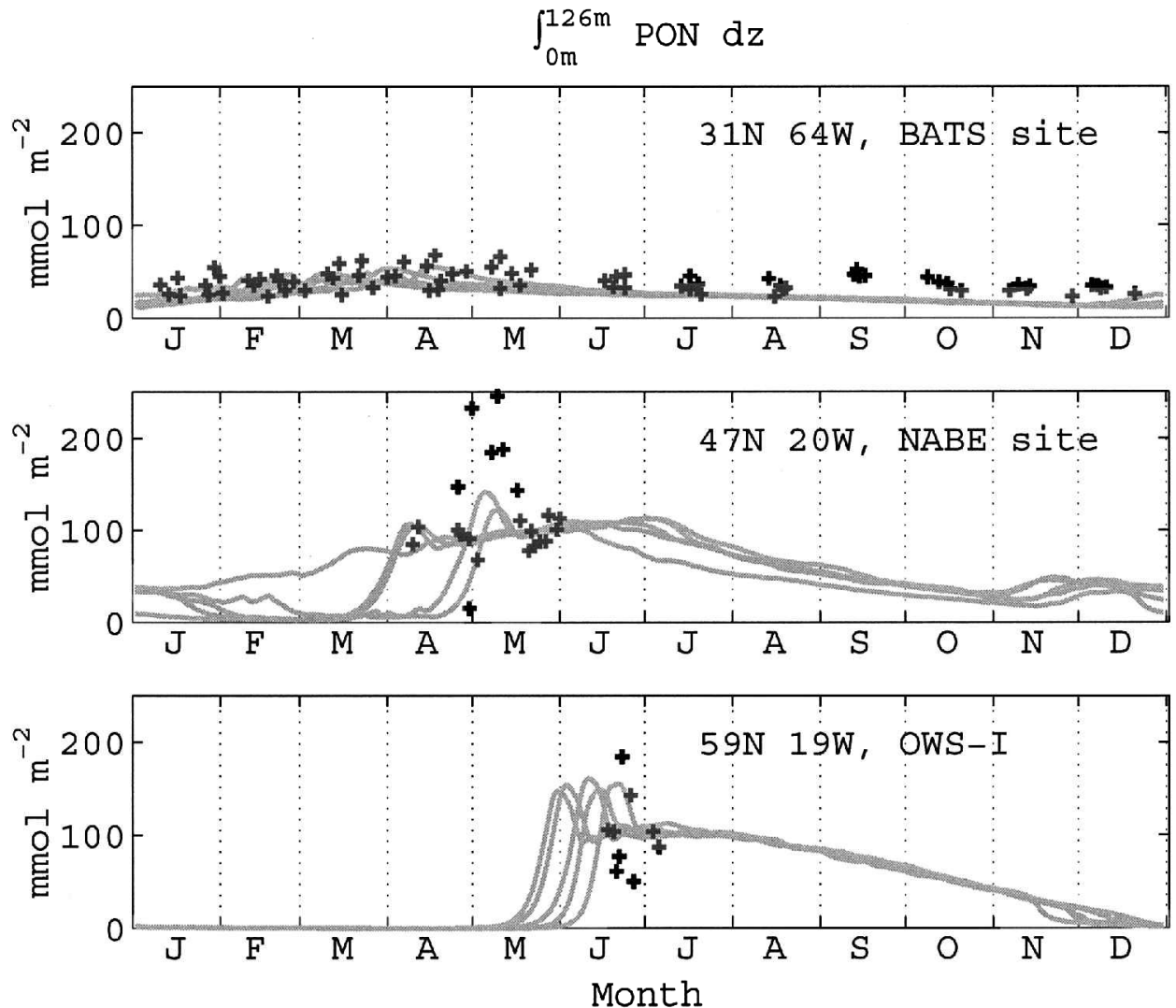

Figure 3. Particulate organic nitrogen (PON) integrated over the upper 126 meters at three North Atlantic sites. Gray lines show model solutions from 1989 through 1993 projected into a single year. Observations are indicated by bold marks. A distinct seasonal cycle in PON is detectable at the NABE site and OWS-INDIA, whereas integrated PON remains almost constant throughout the year near Bermuda.

a noticeable mismatch during September and October, as shown in the upper graph of Figure 3. The modeled zooplankton biomass remains less than $0.05 \mathrm{mmol} \mathrm{N} \mathrm{m}^{-3}$ below 100 meter. Near the surface, maximum concentrations between 0.1 and $0.2 \mathrm{mmol} \mathrm{N} \mathrm{m}^{-3}$ are reached in April and May. These zooplankton concentrations are in agreement with measurements of heterotrophic nano- and microzooplankton (Caron et al., 1995), which entered our optimization procedure. (Modeled zooplankton at the BATS site often exceed the observed biomass near the surface (e.g. Fasham et al., 1993; Doney et al., 1996).) Relatively high PON observations (between 0.2 and $0.3 \mathrm{mmol} \mathrm{N} \mathrm{m}^{-3}$ ) at depths greater than 100 meters may be associated with the significant abundance of bacteria, which are not explicitly accounted for by our model.

At the NABE site, only a few profiles could be procured for PON, i.e. three months, namely April, May and July. Although profiles from July were considered in the 
optimization they are not presented in Figure 3 since their maximum depths do not exceed 80 meters and no vertical integral was calculated. Note first that the model results at the NABE location reveal large year to year changes with respect to the initial build-up of biomass, usually occurring between late March to late April with the exception of 1992. During May the model does not catch up with the observed maximum PON concentrations at the surface. The observations yield concentrations close to $3.7 \mathrm{mmol} \mathrm{N} \mathrm{m}^{-3}$ while the model produces $2.0 \mathrm{mmol} \mathrm{N} \mathrm{m}^{-3}$. Accordingly, the integrated observational PON values in May are higher by a factor of 2. This is in contrast to the good agreement in the magnitude of the DIN draw-down (Table 1). Deficiencies in the simulation of zooplankton biomass must be ruled out as a possible explanation for the too low PON concentrations simulated by the model. The peaks in simulated zooplankton biomass never exceed $1.0 \mathrm{mmol} \mathrm{N} \mathrm{m}^{-3}$ and observed micro-zooplankton biomass ranges from 0.4 to $0.6 \mathrm{mmol} \mathrm{N} \mathrm{m}{ }^{-3}$. Hence, some deficiencies in the model's export dynamics are assumed to be responsible for that particular short-term mismatch in PON. We will come back to this issue in the discussion section.

At OWS-INDIA, PON observations are available for the two summer months June and July, with a maximum PON concentration in July, rendering $1.9 \mathrm{mmol} \mathrm{N} \mathrm{m}^{-3}$ as a monthly average. In general, the model shows high subsurface concentrations with enhanced PON concentrations of $0.2 \mathrm{mmol} \mathrm{N} \mathrm{m}{ }^{-3}$ below 100 meters in August, which mainly reflects the modeled detritus. According to Table 1, mean PON concentrations agree well with the observations. Monthly averages of assimilated zooplankton biomass do not become larger than $0.7 \mathrm{mmol} \mathrm{N} \mathrm{m}^{-3}$ near the surface and $0.05 \mathrm{mmol} \mathrm{N} \mathrm{m}^{-3}$ below 90 meters. In spite of the model results matching the typically observed PON concentrations, inconsistencies may still exist with respect to the separation between the detritus and zooplankton compartments which cannot be resolved by the observational PON data available.

iii. Chlorophyll. Figure 4 shows simulated and observed Chl $a$ concentrations near Bermuda. Monthly averages of the observations are shown as they were implemented in the data-assimilation scheme (see Schartau and Oschlies, this issue). The second panel reveals the remaining residuals between observations and the modeled monthly means after optimization. In order to identify interannual variations, results of the optimized model are also shown for all years of the simulation. Years 1990 through 1991 reveal lower concentrations in Chl $a$ than the others. Although the timing of the spring bloom is in fairly good agreement with observations, Chl $a$ bloom concentrations spread down to over 120 meters in the model. Albeit being less pronounced here, such model-data discrepancies occurred in other models and were already noted by Fasham et al. (1993) and Doney et al. (1996).

During late spring and summer the observed concentrations reveal a deep Chl $a$ maxima (DCM) extending over a greater depth range than the model results. Modeled DCMs are usually restricted to a single grid cell. The modeled DCM extends down to approximately 


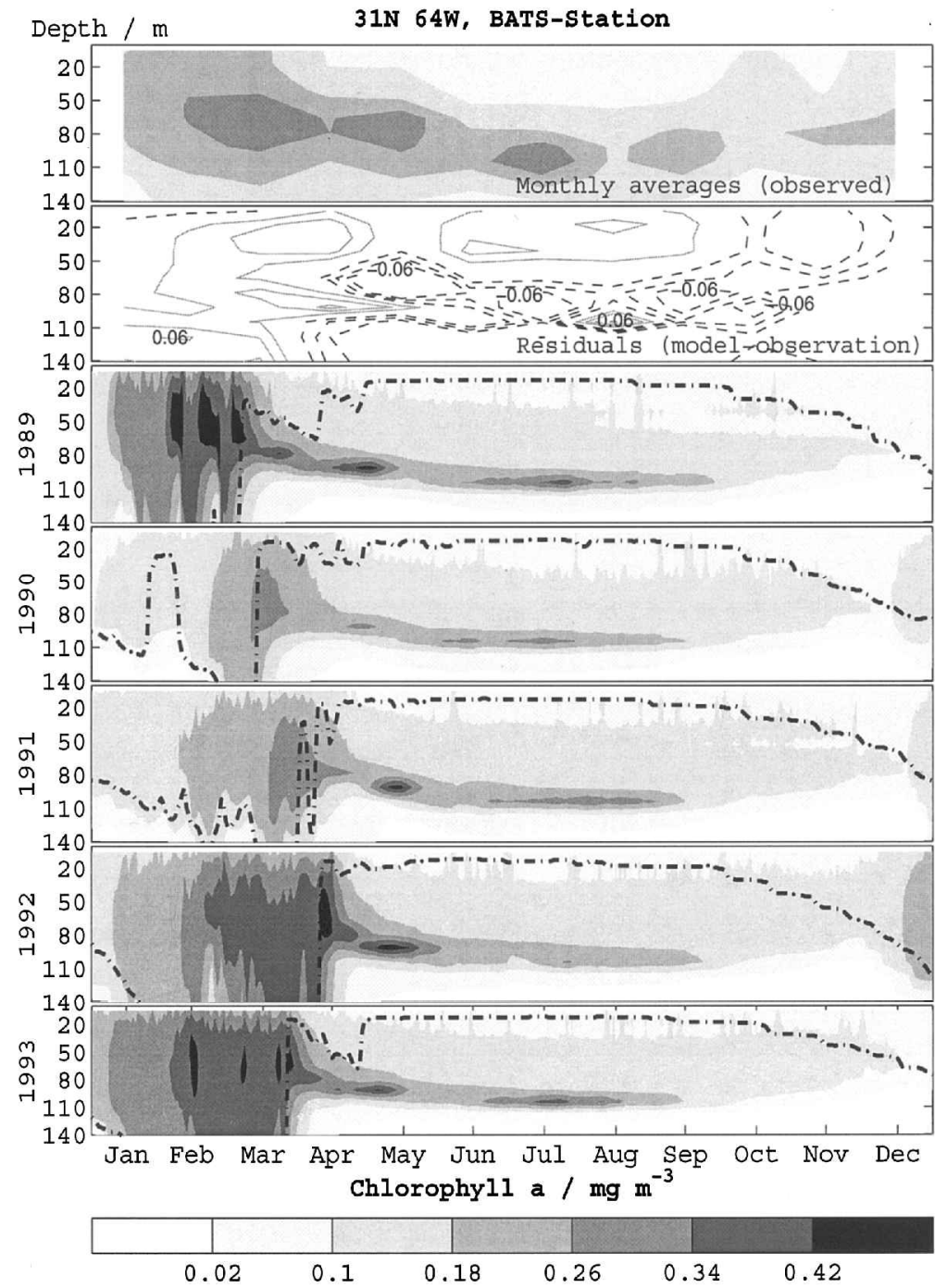

Figure 4. Seasonal cycle of Chl $a$ concentrations $\left[\mathrm{mg} \mathrm{m}^{-3}\right.$ ] at $31 \mathrm{~N} 64 \mathrm{~W}$ (BATS site). The upper panel shows monthly observational data (representatives). The second panel exhibits the residuals (modeled monthly mean of all 5 years minus observation) after optimization. Below, interannual variations of modeled Chl $a$ concentrations are resolved for the years 1989 through 1993. Dash-dotted line indicate modeled mixed layer depths.

100 meters, matching the typical depth at which PAR decreased to $1 \%$ of its surface value (1\% PAR isolume; Sorensen and Siegel, 2001).

Considerable interannual variations are detectable around $47 \mathrm{~N} 20 \mathrm{~W}$ with regard to the timing and intensity of phytoplankton blooms, with the year 1992 showing the extraordi- 


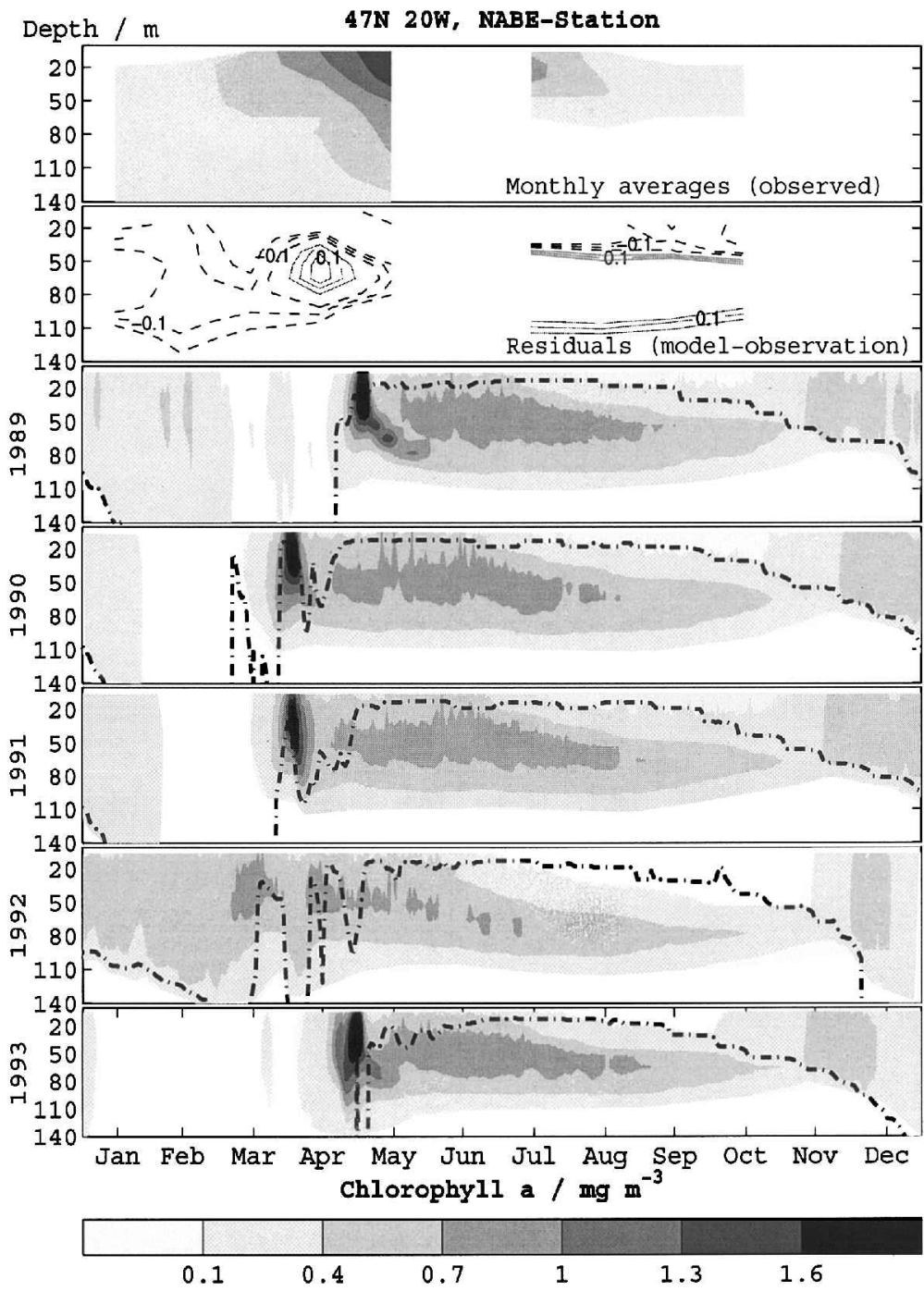

Figure 5. Seasonal cycle of Chl $a$ concentrations $\left[\mathrm{mg} \mathrm{m}^{-3}\right]$ at $47 \mathrm{~N} 20 \mathrm{~W}$ (NABE site). The upper plot shows monthly observational representatives (from January to May and July through October). The second panel exhibits the residuals (modeled monthly mean of all 5 years minus observation) after optimization. Below, model results (daily profiles) are plotted for the years 1989 through 1993. Dash-dotted line indicate modeled mixed layer depths.

nary model solution mentioned before (Fig. 5). The modeled seasonal cycle of Chl $a$ concentrations can be partitioned into three periods. A significant increase in Chl $a$ is generally simulated during April or May. This initial bloom phase lasts about 10 days, which corresponds well to observations from NABE (Lochte et al., 1993). The modeled 
bloom with maxima close to $2.8 \mathrm{mg} \mathrm{Chl} a \mathrm{~m}^{-3}$ is followed by a draw-down which results from an intense grazing pressure on the phytoplankton by zooplankton. For NABE, a distinction between two Chl $a$ maxima can be determined from observations. Fasham and Evans (2000) resolved both maxima by considering silicate and diatoms as individual compartments. The first phytoplankton peak can then be modeled as diatoms which run into silicate limitation and are then replaced by a subsequent nondiatom phytoplankton group. Since our model contains only a single phytoplankton compartment, such a distinction is impossible. It is noteworthy, however, that even in the absence of a co-limiting nutrient like silicate, the model generates two distinct maxima in the time-depth distribution of Chl $a$. Here, interactions between phytoplankton and zooplankton are responsible for this pattern, suggesting that in summer a balance between nutrient supply and the loss set by zooplankton is maintained. During the summer period, the DCM extends from 30 to 60 meters depth, with typical concentrations of $0.8 \mathrm{mg} \mathrm{Chl} a \mathrm{~m}^{-3}$. Eventually, in late October the modeled Chl $a$ concentrations rise again to values of $0.4 \mathrm{mg} \mathrm{Chl} a \mathrm{~m}^{-3}$ until December, representing a fall bloom.

Among the three locations, the OWS-INDIA site exhibits the largest sensitivity to the physical conditions during late spring. The years 1991 and 1993 reveal reduced mixed layer depths at the beginning of May, while other years show only a sustained stratification almost one month later. Figure 6 shows the model's seasonal cycle of Chl $a$ with short intense surface blooms in June. Modeled summer concentrations range from 0.65 to $0.8 \mathrm{mg} \mathrm{Chl} a \mathrm{~m}^{-3}$, whereas measurements are close to $1 \mathrm{mg} \mathrm{Chl} a \mathrm{~m}^{-3}$ throughout the whole summer period. Chl $a$ observations suggest that phytoplankton starts to grow in March and April. In these two months the model is not able to build up any biomass at all. This can be clearly attributed to a delay in stratification in the model. Hence, more nutrients are retained within the model's euphotic zone until June. These elevated nitrate concentrations $\left(15 \mathrm{mmol} \mathrm{N} \mathrm{m}^{-3}\right)$ initiate phytoplankton growth under conditions with PAR levels being higher than in April and May. These two factors lead to an amplified rise in Chl $a$, resulting in a massive simulated biomass built-up in June.

Looking at Figures 4 and 5 we find the development of the DCM as a characteristic property at $31 \mathrm{~N} 64 \mathrm{~W}$ and $47 \mathrm{~N} 20 \mathrm{~W}$. The DCM evolves at depths where nutrients are still available while the PAR remains sufficiently high. Variable Chl $a$-to-nitrogen ratios were suggested to better simulate the $\mathrm{Chl} a$ concentrations together with the PON distribution (Doney et al., 1996; Hurtt and Armstrong, 1999). The empirical function of Cloern et al. (1995), employed by the model generates a variable chlorophyll-carbon ratio. When applying a constant nitrogen to carbon ratio of 6.625 , as suggested by Redfield et al. (1963), this function produces chlorophyll to nitrogen ratios far below $1.56 \mathrm{mg} \mathrm{Chl} a \mathrm{mmol} \mathrm{N}^{-1}$ within the euphotic zone. Near the surface the ratio can be as low as $0.33 \mathrm{mg} \mathrm{Chl} a \mathrm{mmol} \mathrm{N}^{-1}$ during summer when incoming radiation and temperatures are highest. These near-surface ratios are rather low, which might result from our assumption of a fixed carbon-to-nitrogen stoichiometry. Indeed, 


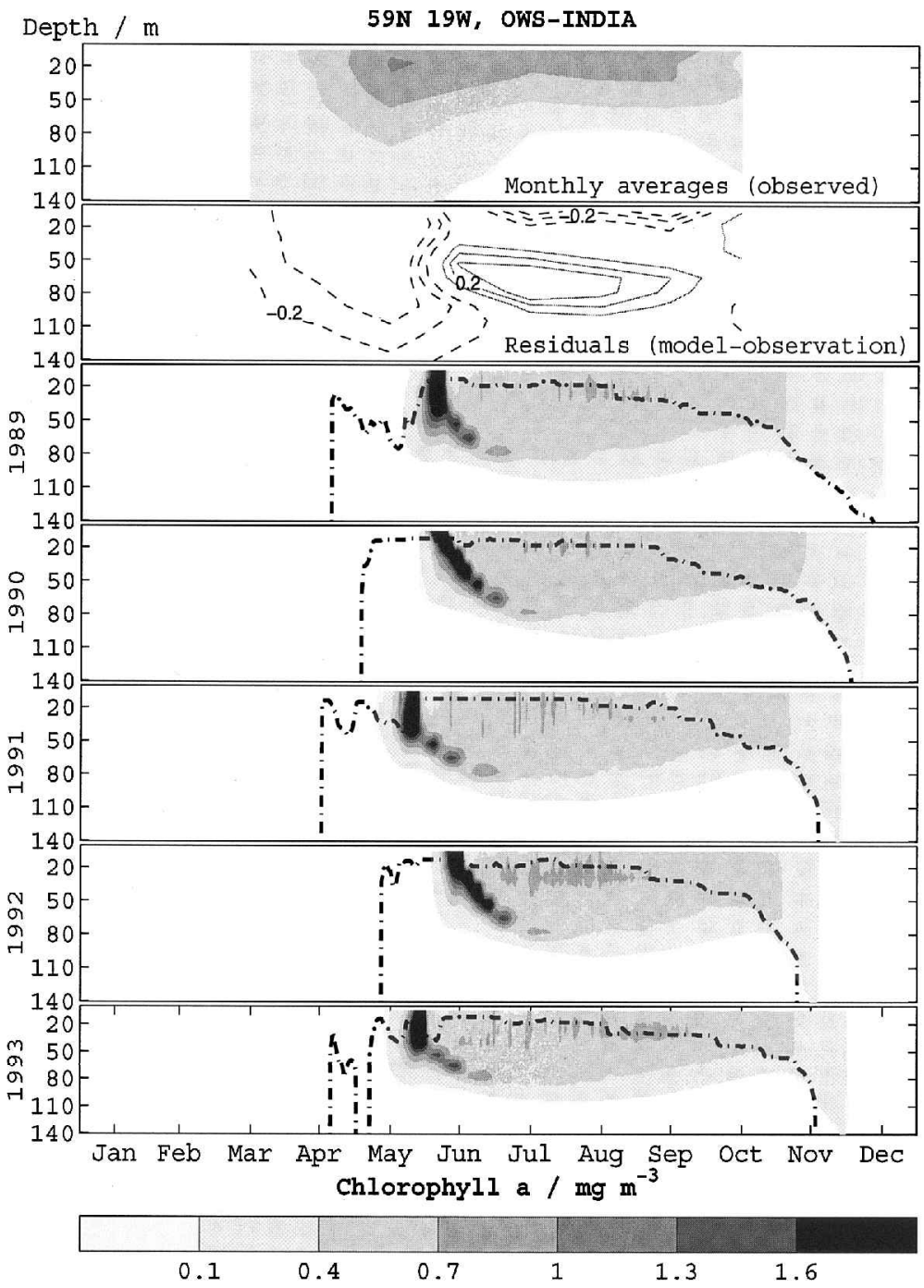

Figure 6. Seasonal cycle of Chl $a$ concentrations $\left[\mathrm{mg} \mathrm{m}^{-3}\right]$ at 59N 19W (OWS-INDIA). The top panel exhibits monthly averages (available for the period March through October). The second panel shows the residuals (modeled monthly mean of all 5 years minus observation) after optimization. Model results (daily profiles) are plotted for the years 1989 through 1993. Dash-dotted line indicate modeled mixed layer depths.

highly variable carbon-to-nitrogen ratios are presumably realistic for the BATS and NABE sites, since carbon assimilation was suggested to continue if there is sufficient light while nutrients are depleted (Sambrotto et al., 1993). We will refer to this possibility in the discussion section. 
Optimized fluxes at three sites in the North Atlantic [mmolN m ${ }^{-2} \mathrm{yr}^{-1}$ ]

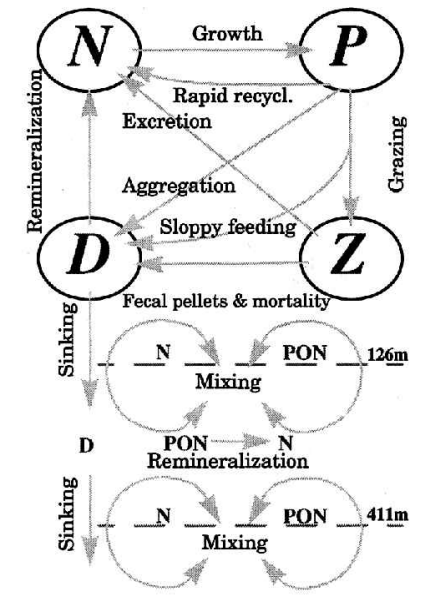

31N 64W, BATS-Station

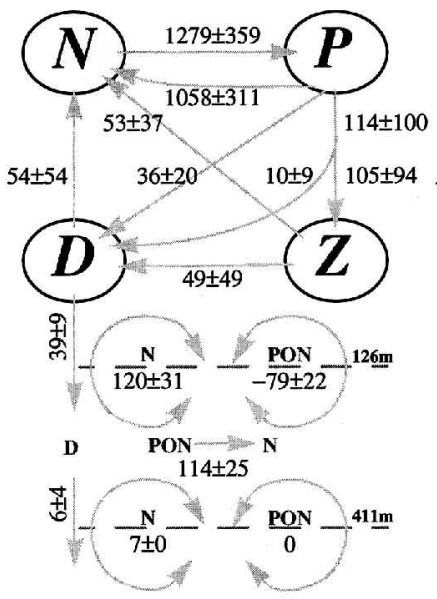

47N 20W, NABE-Station

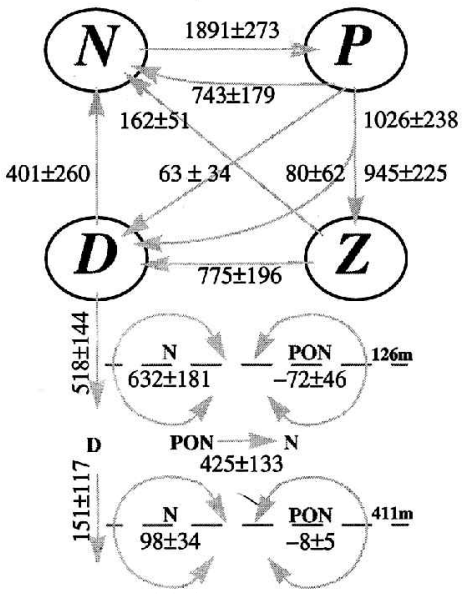

59N 19W, OWS-INDIA

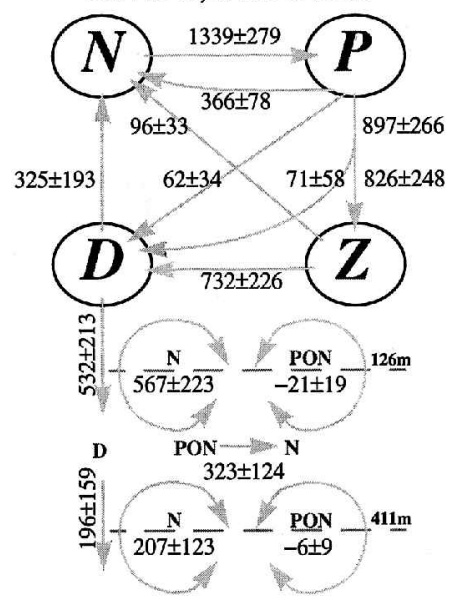

Figure 7. Annual nitrogen fluxes after assimilating observational data into the model. The compartments (state variables) are dissolved inorganic nitrogen $(N)$, phytoplankton biomass $(P)$, herbivorous zooplankton $(Z)$ and detritus $(D)$.

\section{b. Nitrogen fluxes}

Annual fluxes are derived for two depth ranges (I:0 m-126 m, II:126 m-411 m) separated by a level close to the bottom of the euphotic zone. Figure 7 shows optimized annual fluxes together with standard deviations which account for uncertainties in the optimal estimates of model parameters. Note that the model is not in steady state because of 
interannual variations in the physical forcing. Nevertheless, according to the inventories of total annual nitrogen (particulate and inorganic) any annual net gain or loss remains in the range of 1 to $5 \mathrm{mmol} \mathrm{N} \mathrm{m} \mathrm{yr}^{-1}$. Model solutions with a more substantial drift in the upper layer's total nitrogen inventory have been suppressed during the optimization process by adding a mass conservation constraint to the data-model misfit function (Schartau and Oschlies, 2003; this issue).

For all stations, the optimization resulted in a model solution with a large nitrogen flux from phytoplankton back to the inorganic nutrient pool. This flux appears to be most important for the oligotrophic BATS site. In the model the direct link between phytoplankton and nutrient is very rudimentary. Naturally, this simplified parameterization accounts for many processes such as the release of dissolved organic nitrogen (DON) and bacterial activity. Our finding implies that either a very rapid transformation of DON to DIN or the direct DON utilization by phytoplankton are relevant for matching the observations used for data-assimilation. Such a role of bacterial activity was already emphasized in the model study of Spitz et al. (2001) who performed a data-assimilation experiment for the BATS site. An improved model performance was achieved for an enhanced mineralization of dissolved organic matter (DOM), with a preferential bacterial uptake of DON over ammonia. Our optimization results support their hypothesis of bacteria being in competition with phytoplankton for ammonia uptake, with bacteria tending efficiently utilizing DON.

Model studies by Bissett et al. (1999) and Anderson and Williams (1998) also suggest the effective utilization of DON by bacteria. Alternatively, phytoplankton may directly utilize DON as a nutrient source. With our findings we cannot distinguish between a direct utilization of DON by phytoplankton or by bacteria. We can only emphasize the role of a rapid turnover rate for nitrogen near Bermuda and for the NABE site, although less pronounced at the latter. In some previous modeling studies, such as Fasham et al. (1993), Doney et al. (1996) and Schartau et al. (2001), a significant fraction of remineralization occurred via zooplankton, which was mostly attributed to the production of ammonium. These model solutions remain questionable because the associated zooplankton abundances were far too high.

In contrast to Bermuda, the pathway for nutrient recycling via detritus becomes larger at 47N 20W and 59N 19W. Regarding zooplankton, it can be seen that the annual mean phytoplankton losses due to grazing are enhanced when going farther north. The grazing pressure increases by a factor of ten when going from the BATS to the NABE site. Such model behavior is indeed expected and desired. Large nitrogen fluxes from zooplankton to detritus represent the production of fecal pellets which are believed to play a significant role for the annual nitrogen export (Lenz et al., 1993). In fact, the largest export flux in the model is associated with zooplankton. In the model 9\% (at $31 \mathrm{~N} 64 \mathrm{~W}$ ), 54\% (at $47 \mathrm{~N} 20 \mathrm{~W}$ ), and $67 \%$ (at $59 \mathrm{~N} 19 \mathrm{~W}$ ) of the annual primary production are grazed by zooplankton with a large fraction then entering the detritus pool for export.

Table 1 also lists the optimal estimates of the $f$-ratio. According to the model's nitrogen budgets at the BATS and NABE sites and the good agreement with DIN and PON observations, we have obtained very reasonable $f$-ratio approximations. This is also 
supported by comparison with the diagnostic model of Ono et al. (2001) at the BATS site, who determined the seasonal budget of remineralization from oxygen, dissolved inorganic carbon and nitrate measurements. From their model analysis they evaluated a nitrate remineralization of $80 \pm 46 \mathrm{mmol} \mathrm{N} \mathrm{m}^{-2}$ within a 240 days period (from April 16 until December 12) integrated over 100 to 150 meters. Our optimized model yields a mean remineralization of $89 \mathrm{mmol} \mathrm{N} \mathrm{m}^{-2}$ for the same period over a similar depth range. At OWS-INDIA, errors in the physical forcing lead to an $f$-ratio approximation which is too small compared to values reported by Boyd et al. (1997) and Bury et al. (2001). Overall, the model structure and its associated fluxes bring about some noteworthy model behavior. Going from the BATS site toward higher latitudes, we find that the model's sensitivity of total production to changes in the rapid remineralization rates decreases. Total productivity at the oligotrophic BATS site can be raised simply by increasing the ambient temperature because it has quite a direct effect on the rapid recycling rate. Hence, in the model the correlation between temperature and the $f$-ratio is clearly negative near Bermuda where the rapid recycling fuels $83 \%$ of the total production. At the NABE site and at OWS-INDIA such correlations between temperature and the $f$-ratio become much less accentuated for two reasons. One is that the rapid recycling percentages of total production are much lower than at the BATS site, only $39 \%$ and $27 \%$ at $47 \mathrm{~N} 20 \mathrm{~W}$ and $59 \mathrm{~N} 19 \mathrm{~W}$, respectively. Secondly, with increasing latitudes the same temperature changes would usually have a much greater impact on total production due to the interplay of the phytoplankton's maximum possible growth rates, mixing depths, nutrient availability, and light conditions. Apparently, the general model behavior with respect to temperature and $f$-ratio is in accordance with the results of Laws et al. (2000).

In order to compare modeled annual primary production rates with satellite-derived approximations (Table 1) we need to transform from nitrogen to carbon units. For the sake of simplicity we refer to a constant molar nitrogen-to-carbon conversion factor of 6.625 , according Redfield et al. (1963). Surprisingly, the integrated primary production rates of the optimized model are in excellent agreement with various satellite-based estimates (Sathyendranath et al., 1995; Antoine et al., 1996; Behrenfeld and Falkowski, 1997) at the BATS site. Annual primary production of the model becomes maximal for the NABE location where it is still in accordance with the satellite based approximations. A factor of two difference between the satellite estimates and model results exists for OWS-INDIA. This striking discrepancy is mainly due to the shortened period of simulated phytoplankton growth in the absence of light-limited conditions. Again, the mismatch in the physical forcing induces a significant error in the modeled-based approximation of primary production at this high latitude site.

\section{Discussion}

In the previous section we have presented "best" estimates of biogeochemical fluxes at three sites in the North Atlantic that were obtained by optimizing a NPZD-model simultaneously to observations at the respective sites. While most of the data used in the 
optimization process were measurements of standing stocks, the internally consistent model dynamics allow the derivation of elemental fluxes among the model compartments. The simultaneous optimization implicitly assumes that a single model with a single set of (optimized) parameters can adequately describe biogeochemical fluxes in different biogeographical provinces. At first sight, the generally good agreement with integral properties shown above seems to support this assumption. Going into more detail, however, some crucial shortcomings can be specified. The identification and accentuation of model limitations are of special interest, since a precise error specification can guide model refinements and thus justifies an associated increase in model complexity.

\section{a. Model limitations and implications for model improvements}

i. Primary production. The depth-time distribution of simulated primary production rates closely follows the modeled $\mathrm{Chl} a$ concentrations shown in Figures 4, 5, and 6. In fact, the modeled productivity and $\mathrm{Chl} a$ distribution appear to be correlated better than indicated by observations. In general, modeled primary production rates are too low at the surface during summer and too high at greater depths. Hence, the model error is systematic. Such model behavior is most apparent at the BATS and NABE locations. Vertically integrated productivities do not necessarily reveal these misfits. Figure 8 shows the vertically integrated primary production as well as the vertical distribution of ${ }^{14} \mathrm{C}$-based residuals at the Bermuda site where observational coverage is best. For ecosystem models problems may arise in terms of new production and export when the set up is chosen to be solely one-dimensional, meaning that a significant fraction of primary production can be missed in the absence of horizontal mesoscale dynamics. For example, mesoscale features are proposed to increase new production in areas of the Sargasso Sea (Siegel et al., 1999; McGillicuddy et al., 1999; Mahadevan and Archer, 2000). As described by McGillicuddy et al. (1998), the concept of enhanced productivity due to mesoscale variations is based on the idea that eddy-induced upwelling events supply the euphotic zone with new nutrients to be utilized by the phytoplankton. The effect of this process is still debated since it is not yet clear how fast the elevated isopycnals are refilled with nutrients after utilization (Oschlies, 2002; Martin and Pondaven, 2003). Some shortcomings and problems in primary production were also explicitly pointed out in the study of Spitz et al. (1998). Following their interpretation, deficiencies in reproducing primary production could also be attributed to interannual variations since their observational data were compared with the results of a model that was forced with climatological data.

Although unresolved effects of interannual variability and mesoscale dynamics on primary production cannot be ruled out in our one-dimensional model set-up, we suspect that the obvious model error in primary production patterns is due to the inadequacy of applying constant $\mathrm{C}: \mathrm{N}$ ratios to convert simulated phytoplankton nitrogen uptake to carbon-based primary production. The model underestimates primary production near the surface during April, May and June. For the same months, one can infer surface maxima of the effective quantum yield $\Phi_{c}\left(\mathrm{~mol} \mathrm{Cin}^{-1}\right)$ from the study of Sorensen and Siegel 


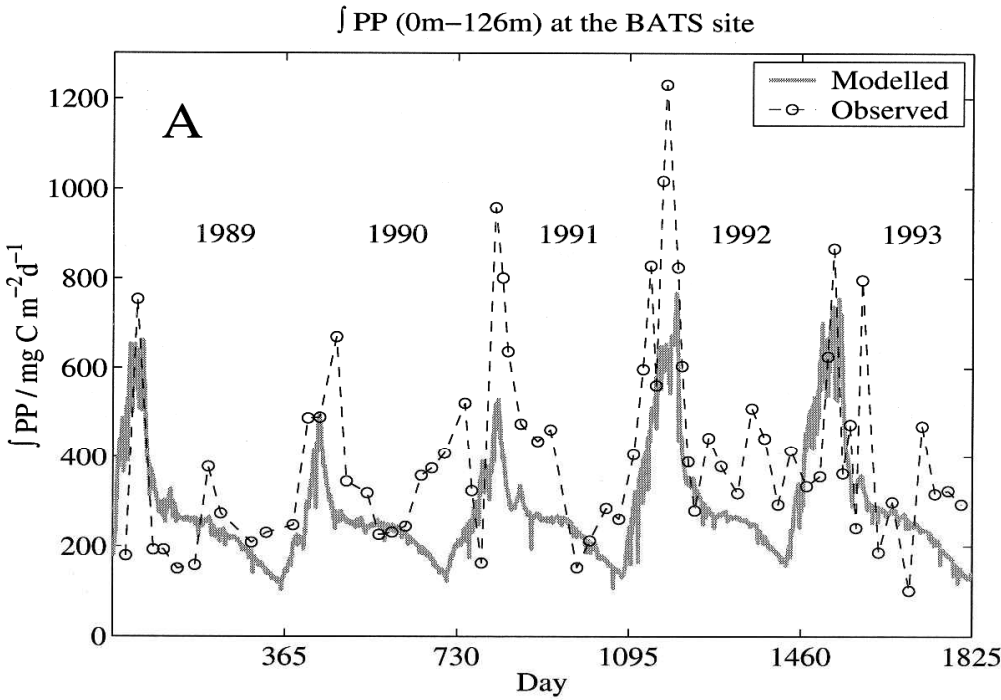

B Residuals in primary production / $\mathrm{mg} \mathrm{C} \mathrm{m}^{-3} \mathrm{~d}^{-1}$

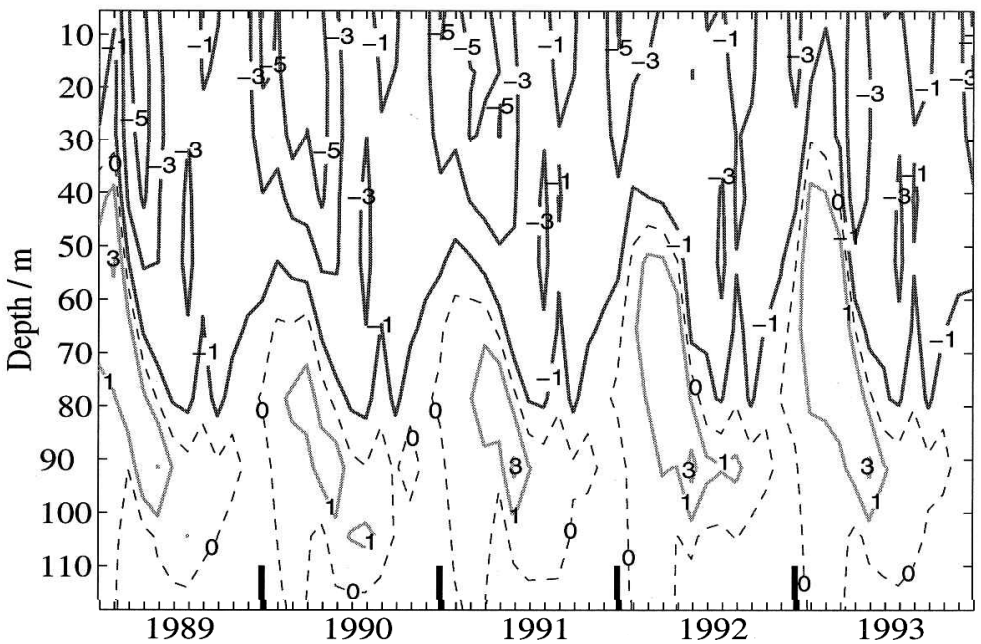

Figure 8. Plot A: Observed and modeled primary production near Bermuda integrated over 126 meters. Modeled counterparts to ${ }^{14} \mathrm{C}$ measurements are determined by a constant molar carbon-tonitrogen ratio of 6.625. Plot B: Residuals in primary production (modeled monthly means minus observations). While integrated productivities seem to be in good agreement, the residuals clearly recover systematic errors in depth distribution.

(2001). They investigated variations of $\Phi_{c}$ for carbon assimilation near Bermuda and found no clear relationship between variations in $\Phi_{c}$ and changes in nitrate concentrations. For our comparison of modeled production rates with those observed, we actually impose such a tight linkage when using a constant $\mathrm{C}: \mathrm{N}$ ratio. Constant $\mathrm{C}: \mathrm{N}$ ratio were also applied 
in Schartau et al. (2001), where measured primary production rates were assimilated into a very simple mixed-layer ecosystem model. It was demonstrated that by no means (either with or without additional constraints on zooplankton) the model could reproduce the observed maximum in primary production that immediately followed the decline in Chl $a$. The model deficiency was shown to be clearly related to post-bloom periods. Elevated C:N stoichiometry over nitrogen uptake was well documented for post-bloom conditions found on a $20 \mathrm{~W}$ transect in the North Atlantic by Körtzinger et al. (2001). Their calculations for new production revealed an overconsumption of nitrogen during the early stages of a spring bloom whereas a clear excess of carbon over nitrogen uptake was found under nitrate depletion. The model obviously misses variations in the phytoplankton's C:N stoichiometry. Nevertheless, additional problems arise when modeled phytoplankton production rates are directly compared with ${ }^{14} \mathrm{C}$-primary production measurements. Following Karl et al. (1998), the ${ }^{14} \mathrm{C}$-primary production incubation measurements underestimate carbon acquisition by phytoplankton, especially under oligotrophic conditions. In their study, the interplay of freshly exudated dissolved organic carbon (DOC) and its utilization by bacteria was shown to be sensitive to the incubation period and hence influenced the POC measurement. Such effects are unresolved by the model. Furthermore, in a study by Engel et al. (2002), it was demonstrated how an excess carbon production, deviating from Redfield stoichiometry, can subsequently be transformed into particulate organic carbon (POC). This further indicates that carbon uptake by phytoplankton cannot simply be derived from modeled nitrogen-based productivities multiplied by a constant $\mathrm{C}: \mathrm{N}$ ratio. The model mismatch is likely due to the diagnostics of carbon-based primary production rather than an error in the modeled nitrogen acquisition by phytoplankton. This also explains our excellent (nitrogen-based) $f$-ratio estimates for the BATS and NABE sites in spite of the apparent errors in (carbon-based) primary production.

To formulate an ecosystem model with carbon fluxes being decoupled from nitrogen is not new and several model studies have already been performed, e.g. Bissett et al. (1999) and Anderson and Williams (1998). A solid basis for parameterizing acclimation effects of phytoplankton to varying physical conditions and to changes in nutrient availability is provided by the paper of Geider et al. (1998). Their basic parameterizations have been adopted for the study of Moore et al. (2001) in which an extended ecosystem model is proposed to be applicable for global simulations of phytoplankton dynamics within the mixed layer. As an alternative to resolving both carbon and nitrogen separately in biogeochemical models, one might also consider the development of some sophisticated diagnostics to convert from modeled nitrogen or phosphorus fluxes to carbon fluxes. Such an approach would be of great value, since it would allow for a reanalysis of some old runs of purely nitrogen- or phosphorus-based models.

ii. Particle export. As for modeling primary production under oligotrophic conditions, care is needed when interpreting the modeled export rates when a constant sinking speed of detritus is employed and effects like coagulation are disregarded (Jackson, 2001). Here, we 


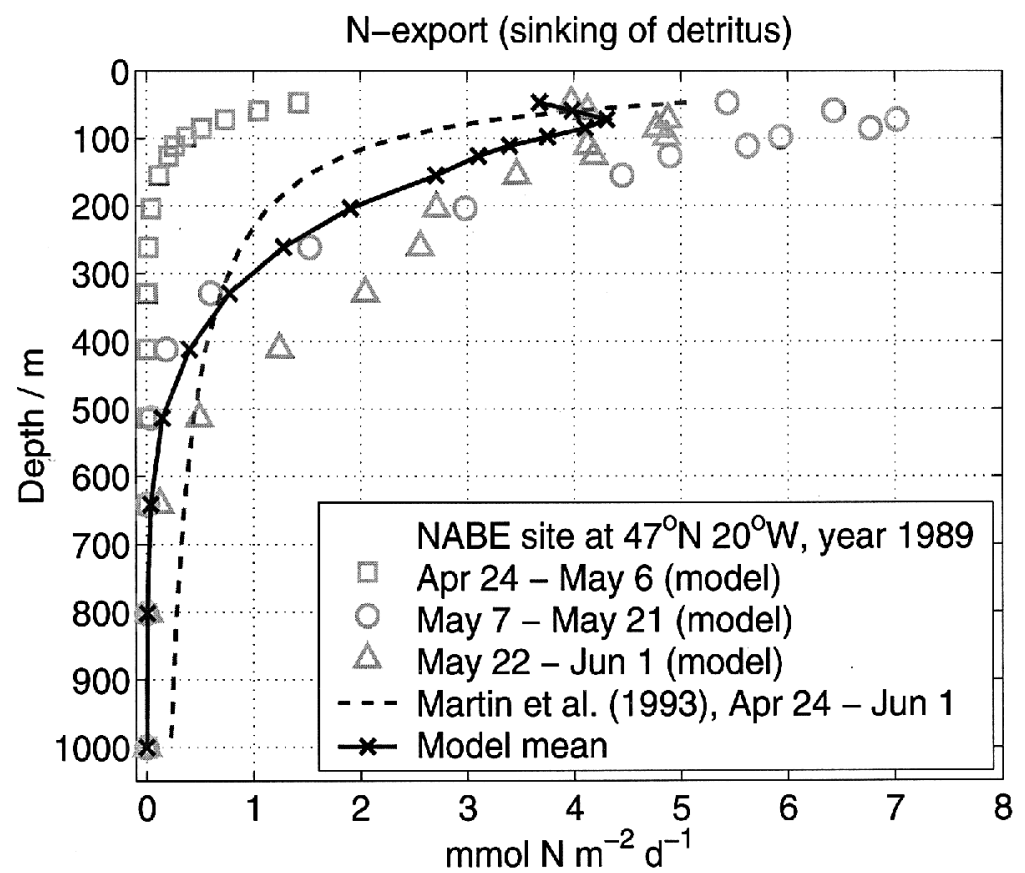

Figure 9. Nitrogen export rates for the period April 24 through June 1. The modeled export rate is calculated from the sinking flux of detritus. For intercomparison the individual flux intervals are chosen to be similar with the periods described in Martin et al. (1993).

compare the modeled vertical nitrogen export with flux rates obtained by Martin et al. (1993) at 47N 20W. Figure 9 displays the nitrogen export of the model, averaged over the same periods as observed. The observed export rate for the period April 24 to June 1 was $39 \mathrm{mmol} \mathrm{C} \mathrm{m} \mathrm{d}^{-2} \mathrm{~d}^{-1}$ at 35 meters depth. When applying a constant molar carbon-tonitrogen ratio of $\mathrm{C}: \mathrm{N}=6.625$, the modeled counterpart is only $22 \mathrm{mmol} \mathrm{C} \mathrm{m}{ }^{-2} \mathrm{~d}^{-1}$. However, Martin et al. (1993) point out that the power function applied gives trustworthy estimates only for the depth range of 150 to 2000 meters. The vertical profile of modeled nitrogen export in Figure 9 intersects the power function profile at two depths. Simulated export rates are largest within the euphotic zone (approximately at 60 meters) where concentrations of detritus are largest. Above 60 meters, the modeled fluxes are smaller than fluxes derived from the power function. Between 60 and 330 meters the model preserves more PON, keeping the averaged export flux higher than estimated from the power function. This means that either remineralization rates derived from the trap measurements are too high for the upper 300 meters or the model underestimates regeneration in this depth range.

Below 330 meters, the modeled export flux becomes smaller than the observed one. A simple explanation like the sinking velocity being too low $\left(18 \mathrm{~m} \mathrm{~d}^{-1}\right)$ must be rejected since the model would otherwise become unbalanced in mass fluxes. In addition, it would 
also yield larger misfits in PON and Chl $a$ concentrations. A more likely explanation is that pulses of rapidly sinking particle aggregates, overlap a more continuous export process with somewhat lower sinking rates. Particle aggregates with high sinking velocities (Alldredge and Gotschalk, 1989) can lead to large and deep export fluxes, being better captured by deep traps during a bloom event. On the other hand, smaller and slowly sinking particles are present within the euphotic layer at all times as long as primary production takes place.

Looking at the seasonal cycle of the export flux, as well as at changes in phytoplankton size spectra and in community structure, the question arises: How must empirically derived export curves for annual or longer-term average fluxes be interpreted and applied for data-assimilation? The study of Armstrong et al. (2002) shows improved fits to observed POC fluxes when splitting up an export function into two terms. One term is responsible for the deep export flux and is associated with the ballast minerals such as silicate or calcite frustuls. Our model simply contains a single homogeneous pool of sinking detritus. The effective sinking velocity obtained during optimization is surely too slow for phytoplankton aggregates and too high for single cells. This generates reasonable export fluxes down to 400 meters, but then the model underestimates the export flux at greater depths.

While it is unlikely that an ecosystem model with a single detritus compartment and constant sinking velocity can produce reliable vertical export profiles, applying more sophisticated coagulation equations together with algal growth (e.g. Jackson, 2001) is yet impossible for large-scale modeling. Instead, some computationally more efficient, idealized parameterizations for the formation and sinking of particle aggregates have already been proposed (e.g. Kriest and Evans, 1999 or Ruiz et al., 2002). Future data assimilation studies will show whether these can improve model results.

iii. Physical forcing. Among the three model locations, discrepancies between observed and simulated mixed layer depths are largest at the northernmost site, OWS-INDIA. This site is influenced by the North Atlantic Current system which transports subtropical water northward. Generally, winter mixed layers reach depths between 400 and 600 meters. The model's maximum mixing depths are close to 1000 meters. One reason for this discrepancy may be the fact that the years of observations (1971-1974) show a low index phase for the North Atlantic Oscillation (NAO), whereas the ECMWF forcing (1989-1993), which is applied here, covers a period with a high NAO index. Simulations under different NAO conditions (Oschlies, 2001) indeed revealed decreased mixing in the region of OWSINDIA for low NAO periods, mainly due to changes in westerly winds. This suggests that the discrepancy between observed and simulated winter mixed layer depths can, to some extent, be attributed to different phases of the NAO.

At OWS-INDIA, the mixed layer is deepest in March and a continuous stabilization of the water column is established by the beginning of May. The observed chlorophyll concentrations suggest early phytoplankton growth in March and April. Measurements comprise a wide range for the timing of the onset of the initial "bloom," presumably 
because of patchiness and interannual variations. However, Chl $a$ concentrations above $0.5 \mathrm{mg} \mathrm{m}^{-3}$ were observed in early spring. Obviously, physical processes which are not resolved by the model cause an early biological signal. One explanation would be the horizontal advection of a Chl $a$ from farther south where phytoplanktongrowth has already been initiated. Likewise, diurnal changes of the mixed layer depths, which may play a significant role in sustaining phytoplankton growth at high latitudes (e.g. Woods and Onken 1982; Wolf and Woods, 1988) are not resolved by the model. Short-term bloom events (ephemeral blooms) were also suggested as major reason for an early Chl $a$ increase by Longhurst (1998), referring to observations made by Williams (1988) and Dickey (1994). A deep excursion of high chlorophyll concentrations at the end of April and in May was observed in all four years (Williams, 1988). This might be caused by sinking phytoplankton cells (Longhurst, 1998) or by episodical mixing events that export Chl $a$ to great depths (Gardner et al., 1993).

\section{Summary and conclusion}

Judged by its ability to match standing stock observations and satellite-derived estimates of primary production, the NPZD-model seems reasonably successful at the BATS and NABE locations but reveals major weaknesses at the northernmost site OWS-INDIA. This shortcoming could be associated with deficiencies in the applied physical forcing taken from a basin-scale ocean circulation model. However, the model was still capable of capturing some basic dynamics of the prevailing nitrogen fluxes. The optimized model yields very good approximations of the $f$-ratio, in particular at the BATS and NABE sites. Although we can state that, in general, a single model can indeed be applied to sites with different biogeochemical characteristic, a careful identification and analysis of model deficiencies is important. A precise error specification can then guide model refinements. In particular, data assimilation studies like this help to assess whether the cost of an increased model complexity (and increased number of model parameters) actually pays off in the formation of a better model fit to the data.

The optimized model results yielded large fluxes of organic nitrogen back to its inorganic form, with phytoplankton being the dominant organic source. This flux appeared to be important particularly for getting reliable estimates of the $f$-ratio. With respect to $a$ priori, nonoptimized model, this results in enhanced primary production at all three locations. The NPZD-model's direct nitrogen flux from phytoplankton back to DIN is a rudimentary representation of the recycling processes involved, and a more sophisticated formulation may help to improve the model, possibly including the formation and fate of dissolved organic matter.

It was found that an intercomparison of vertically and temporally integrated primary production rates may be an insufficient and even misleading model assessment. In spite of good agreement between modeled integrated primary production and satellite-derived estimates at the BATS and NABE sites, severe systematic model errors remain in the vertical and temporal patterns of primary production. These errors are largest under 
nutrient-depleted conditions, especially at high light intensities near the surface. Data of ${ }^{14} \mathrm{C}$-derived primary production can deviate from primary production rates of the nitrogen based NPZD-model. Our results agree with previous findings that carbon acquisition by phytoplankton must be decoupled from nitrogen uptake in ecosystem models in order to allow for reasonable carbon flux estimates.

Vertical profiles of simulated export fluxes showed some systematic differences with empirically derived fits to sediment trap data. Although observational estimates are subject to systematic errors, the model-data discrepancy nevertheless suggests that the simple formulation, with a single type of particles sinking with a constant sinking velocity, is not well suited to describe deep particle export. Some more sophisticated algorithms (e.g. coagulation and aggregation) are already available. Whether they constitute a significant model improvement remains to be tested.

A tight link of physical-biological interactions appear to be of greater importance at the OWS-INDIA site than at the locations of BATS and NABE. Such a linkage is suspected to be primarily associated with diurnal variability in physics and biology. To some extent, model discrepancies in spring can be assigned to interdecadal variabilities and hence differences in heat fluxes and mixing. For this reason, it may be problematic to fall back on measurements from the early seventies for a model assessment.

Acknowledgments. We thank everyone involved in obtaining the observations made available to us. Many helpful suggestions were made by the referees and we greatly acknowledge their efforts in reviewing our manuscript. We would also like to thank Christoph Voelker and Anja Engel for their comments on an early version of the manuscript. The work presented in this paper was partly supported by the Deutsche Forschungsgemeinschaft (DFG).

\section{REFERENCES}

Alldredge, A. L. and C. Gotschalk. 1989. Direct observations of mass flocculation of diatom blooms: characteristics, settling velocities and formation of diatom aggregates. Deep-Sea Res. I, 36, $159-171$.

Anderson, T. and P. B. Williams. 1998. Modelling the seasonal cycle of dissolved organic carbon at station E1 in the English Channel. Estuar. Coastal Shelf Sci., 46, 93-109.

Antoine, D., J.-M. André and A. Morel. 1996. Oceanic primary production. 2. Estimation at global scale from satellite (coastal zone color scanner) chlorophyll. Global Biogeochem. Cycles, 10, $57-69$.

Armstrong, R. A., C. Lee, J. I. Hedges, S. Honjo and S. G. Wakeham. 2002. A new, mechanistic model for organic carbon fluxes in the ocean based on the quantitative association of POC with ballast minerals. Deep-Sea Res. II, 49, 219-236.

Behrenfeld, M. and P. Falkowski. 1997. A consumer's guide to phytoplankton primary productivity models. Limnol. Oceanogr., 42, 1479-1491.

Bissett, W., J. Walsh, D. Dieterle and K. Carder. 1999. Carbon cycling in the upper waters of the Sargasso Sea: I. Numerical simulations of different carbon and nitrogen fluxes. Deep-Sea Res. I, 46, 205-269.

Boyd, P., A. Pomroy, S. J. Bury, G. Savidge and I. Joint. 1997. Micro-algal carbon and nitrogen uptake in post-coccolithophore bloom conditions in the NE Atlantic, July, 1991. Deep-Sea Res. I, 44, 1497-1517.

Buesseler, K. O., M. P. Bacon, J. K. Cochran and H. D. Livingston. 1992. Carbon and nitrogen export 
during the JGOFS North Atlantic Bloom Experiment estimated from ${ }^{234} \mathrm{Th}^{238} \mathrm{U}$ disequilibria. Deep-Sea Res., 39, 1115-1137.

Bury, S. J., P. W. Boyd, T. Preston, G. Savidge and N. J. P. Owens. 2001. Size-fractionated primary production and nitrogen uptake during a North Atlantic phytoplankton bloom: implications for carbon export estimates. Deep-Sea Res. I, 48, 689-720.

Caron, D. A., H. G. Dam, P. Kremer, E. J. Lessard, L. P. Madin, T. C. Malone, J. M. Napp, E. R. Peele, M. R. Roman and M. J. Youngbluth. 1995. The contribution of microorganisms to particulate carbon and nitrogen in surface waters of the Sargasso Sea near Bermuda. Deep-Sea Res. I, 42, 943-972.

Cloern, J. E., C. Grenz and L. Vidergar-Lucas. 1995. An empirical model of the phytoplankton chlorophyll:carbon ratio- the conversion factor between productivity and growth rate. Limnol. Oceanogr., 40, 1313-1321.

Conkright, M. E., S. Levitus and T. B. Boyer. 1994. World Ocean Atlas 1994, Vol. 1: Nutrients. National Oceanic and Atmospheric Administration Atlas NESDIS 1, U.S. Gov. Print. Office, Washington, D.C, 162 pp.

Dickey, T. 1994. Bio-optical and physical variability in the subarctic North Atlantic Ocean during the spring of 1989. J. Geophys. Res., 99, 22541-22556.

Doney, S. C., D. Glover and R. Najjar. 1996. A new coupled, one-dimensional biological-physical model for the upper ocean: Applications to the JGOFS Bermuda Atlantic Time-Series Study (BATS) site. Deep-Sea Res. II, 43, 625-651.

Doney, S. C., J. Kleypas, J. Sarmiento and P. Falkowski. 2002. The US JGOFS synthesis and modeling project—an introduction. Deep-Sea Res. II, 49, 1-20.

Ducklow, H. W. and R. P. Harris. 1993. Introduction to the JGOFS North Atlantic bloom experiment. Deep-Sea Res. II, 40, 1-8.

Engel, A., S. Goldthwait, U. Passow and A. Alldredge. 2002. Temporal decoupling of carbon and nitrogen dynamics in a mesocosm diatom bloom. Limnol. Oceanogr., 47, 753-761.

Evans, G. T. 1999. The role of local models and data sets in the Joint global Ocean Flux Study. Deep-Sea Res. I, 46, 1369-1389.

Fasham, M. J. R. and G. T. Evans. 2000. Advances in ecosystem modelling within JGOFS, in The Changing Ocean Carbon Cycle, R. B. Hanson, H. W. Ducklow and J. G. Field, eds., Cambridge University Press, 417-446.

Fasham, M. J. R., J. L. Sarmiento, R. D. Slater, H. W. Ducklow and R. Williams. 1993. Ecosystem behaviour at Bermuda Station "S" and Ocean Weather Station "India": A general circulation model and observational analysis. Global Biogeochem. Cycles, 7, 379-415.

Gardner, W. D., I. D. Walsh and M. R. Richardson. 1993. Biophysical forcing of particle production and distribution during a spring bloom in the North Atlantic. Deep-Sea Res. II, 40, 171-195.

Garside, C. and J. C. Garside. 1993. The $f$-ratio on $20 \mathrm{~W}$ during the North Atlantic Bloom Experiment. Deep-Sea Res. II, 40, 75-90.

Gaspar, P., Y. Gregoris and J. M. Lefevre. 1990. A simple eddy kinetic energy model for simulations of the oceanic vertical mixing: tests at station Papa and Long-Term Upper Ocean Study site. J. Geophys. Res., 95, 16179-16193.

Geider, R. J., H. L. MacIntyre and T. M. Kana. 1998. A dynamic regulatory model of phytoplankton acclimation to light, nutrients, and temperature. Limnol. Oceanogr., 43, 679-694.

Hurtt, G. C. and R. Armstrong. 1996. A pelagic ecosystem model calibrated with BATS data. Deep-Sea Res. II, 43, 653-683.

-1999. A pelagic ecosystem model calibrated with BATS and OWS-INDIA data. Deep-Sea Res. I, 46, 27-61.

Jackson, G. A. 2001. Effect of coagulation on a model planktonic food web. Deep-Sea Res. I, 48, 95-123. 
Karl, D., D. Hebel, K. Bjorkman and R. Letelier. 1998. The role of dissolved organic matter exudation in the productivity of the oligotrophic North Pacific Gyre. Limnol. Oceanogr., 43, 1270-1286.

Körtzinger, A., W. Koeve, P. Kähler and L. Mintrop. 2001. C:N ratios in the mixed layer during the productive season in the northeast Atlantic Ocean. Deep-Sea Res. I, 48, 661-688.

Kriest, I. and G. T. Evans. 1999. Representing phytoplankton aggregates in biogeochemical models. Deep-Sea Res. I, 46, 1841-1859.

Laws, A. L., P. G. Falkowski, W. O. Smith, H. D. Ducklow and J. J. McCarthy. 2000. Temperature effects on export production in the open ocean. Global Biogeochem. Cycles, 14/4, 1231-1246.

Lenz, J., A. Morales and J. Gunkel. 1993. Mesozooplanktonstanding stock during the North Atlantic spring bloom study in 1989 with evaluation of its potential grazing pressure: a comparison between low, medium and high latitudes. Deep-Sea Res. II, 40, 559-572.

Levitus, S. and T. B. Boyer. 1994. World Ocean Atlas 1994, Vol. 4: Temperature. National Oceanic and Atmospheric Administration Atlas NESDIS 4, U.S. Gov. Print. Office, Washington, D.C, 129 pp.

Lochte, K., H. W. Ducklow, M. J. R. Fasham and C. Stienen. 1993. Plankton succession and carbon cycling at 47N 20W during the JGOFS North Atlantic Bloom Experiment. Deep-Sea Res. II, 40, 91-114.

Longhurst, A. 1998. Ecological Geography of the Sea, Academic Press.

Mahadevan, A. and D. Archer. 2000. Modeling the impact of fronts and mesoscale circulation on the nutrient supply and biogeochemistry of the upper ocean. J. Geophys. Res., 105(C1), 1209-1225.

Marra, J. and C. Ho. 1993. Initiation of the spring bloom in the northeast Atlantic (47N, 20W): a numerical simulation. Deep-Sea Res. II, 40, 55-73.

Martin, A. P. and P. Pondaven. 2003. On estimates for the vertical nitrate flux due to eddy-pumping. J. Geophys. Res., 108(C11), 3359.

Martin, J. H., S. E. Fitzwater, R. M. Gordon, C. N. Hunter and S. J. Tanner. 1993. Iron, primary production and carbon-nitrogen flux studies during the JGOFS North Atlantic Bloom Experiment. Deep-Sea Res. II, 40, 115-134.

McGillicuddy Jr., D. J., R. Johnson, D. A. Siegel, A. F. Michaels, N. R. Bates and A. H. Knap. 1999. Mesoscale variations of biogeochemical properties in the Sargasso Sea. J. Geophys. Res., 104(C6), 13382-13394.

McGillicuddy Jr., D. J., A. R. Robinson, D. A. Siegel, H. W. Jannasch, R. Johnson, T. D. Dickey, J. McNeil, A. F. Michaels, N. R. Bates and A. H. Knap. 1998. Influence of mesoscale eddies on new production in the Sargasso Sea. Nature, 394, 236-266.

Moore, K. J., S. C. Doney, J. A. Kleypas, M. David and I. Y. Fung. 2001. An intermediate complexity marine ecosystem model for the global domain. Deep-Sea Res. II, 49, 403-462.

Ono, S., R. G. Najjar and N. R. Bates. 2001. Shallow remineralization in the Sargasso Sea estimated from seasonal variations in oxygen, dissolved inorganic carbon and nitrate. Deep-Sea Res. II, 48, $1567-1582$.

Oschlies, A. 2001. NAO-induced long-term changes in nutrient supply to the surface waters of the North Atlantic. Geophys. Res. Lett., 28, 1751-1754.

-2002. Can eddies make ocean deserts bloom? Global Biogeochem. Cycles, 16, 1029/ $2001 \mathrm{~GB} 001830$.

Oschlies, A. and V. Garçon. 1998. Eddy-induced enhancement of primary production in a model of the North Atlantic Ocean. Nature, 394, 266-269.

-1999. An eddy-permitting coupled physical-biological model of the North Atlantic. 1. Sensitivity to advection numerics and mixed layer physics. Global Biogeochem. Cycles, 13, 135-160.

Oschlies, A., W. Koeve and V. Garçon. 2000. An eddy-permitting coupled physical-biological model 
of the North Atlantic. 2. Ecosystem dynamics and comparison with satellite and JGOFS local studies data. Global Biogeochem. Cycles, 14, 499-523.

Redfield, A. C., B. H. Ketchum and F. A. Richards. 1963. The influence of organisms on the composition of seawater, in The Sea. 2, M. N. Hill, ed., Wiley, Interscience, NY, 1-34.

Ruiz, J., L. Prieto and F. Ortegón. 2002. Diatom aggregate formation and fluxes: a modeling analysis under different size-resolution schemes and with empirically determined aggregation kernels. Deep-Sea Res. I, 49, 495-515.

Sambrotto, R. N., G. Savidge, C. Robinson, P. Boyd, T. Takahashi, D. Karl, C. Langdon, D. Chipman, J. Marra and L. Codespoti. 1993. Elevated consumption of carbon relative to nitrogen in the surface ocean. Nature, 363, 248-250.

Sarmiento, J. L., R. D. Slater, M. J. R. Fasham, H. W. Ducklow, J. R. Toggweiler and G. T. Evans. 1993. A seasonal three-dimensional ecosystem model of nitrogen cycling in the North Atlantic euphotic zone. Global Biogeochem. Cycles, 7, 417-450.

Sathyendranath, S., A. Longhurst, C. M. Caverhill and T. Platt. 1995. Regionally and seasonally differentiated primary production in the north atlantic. Deep-Sea Res. I, 42, 1773-1802.

Schartau, M. and A. Oschlies. 2003. Simultaneous data-based optimization of a 1D-ecosystem model at three locations in the North Atlantic Ocean: Part 1 Method and parameter estimates. J. Mar. Res., 61, 765-793.

Schartau, M., A. Oschlies and J. Willebrand. 2001. Parameter estimates of a zero-dimensional ecosystem model applying the adjoint method. Deep-Sea Res. II, 48, 1769-1800.

Siegel, D. A., D. J. McGillicuddy and E. A. Fields. 1999. Mesoscale eddies, satellite altimetry, and new production in the Sargasso Sea. J. Geophys. Res., 104(C6), 13359-13379.

Six, K. and E. Maier-Reimer. 1996. Effects of plankton dynamics on seasonal carbon fluxes in an ocean general circulation model. Global Biogeochem. Cycles, 10, 559-583.

Sorensen, J. and D. Siegel. 2001. Variability of the effective quantum yield for carbon assimilation in the Sargasso Sea. Deep-Sea Res. II, 48, 2005-2035.

Spitz, Y. H., J. R. Moisan and M. R. Abbott. 2001. Configuring an ecosystem model using data from the Bermuda Atlantic Time Series (BATS). Deep-Sea Res. II, 48, 1733-1768.

Spitz, Y. H., J. R. Moisan, M. R. Abbott and J. G. Richman. 1998. Data assimilation and a pelagic ecosystem model: parameterization using time series observations. J. Mar. Syst., 16, 51-68.

Volk, T. and M. Hoffert. 1985. Ocean carbon pumps: analysis of relative strengths and efficiencies in ocean-driven atmospheric $\mathrm{CO}_{2}$ changes, in The Carbon Cycle and Atmospheric $\mathrm{CO}_{2}$ : Natural Variations Archean to Present, E. T. Sundquist and W. S. Broecker, eds., Geophysical Monograph 32, American Geophysical Union, Washington, D.C., 99-110.

Williams, R. 1988. Spatial heterogeneity and niche differentiationin oceanic zooplankton. Hydrobiologia, 167/168, 151-159.

Wolf, K. U. and J. D. Woods. 1988. Langragian simulation of primary production in the physical environment-The deep chlorophyllmaximum and thermocline, in Toward a Theory of BiologicalPhysical Interactions in the Worlds Ocean, B. J. Rothschild, ed., Reidel, Dordrecht, 51-70.

Woods, J. D. and R. Onken. 1982. Diurnal variation and primary production in the oceanpreliminary results of a Lagrangian ensemble model. J. Plank. Res., 4, 735-756.

Received: 19 August, 2002; revised: 23 December, 2003. 